\section{SUICIDIO EN AZUL CON NEGRA MANCHA. BREVE HISTORIA DE UN BALAZO EN LA PINTURA DE PABLO PICASSO}

\author{
Ivan Godoy C. \\ Universidad Finis Terrae \\ Marcel Duhaut 2870, depto. 23, Providencia \\ Santiago de Chile \\ chilenodel59@gmail.com
}

\section{SUICIDE IN BLUE WITH BLACK STAIN. SHORT HISTORY OF A GUNSHOT IN THE PAINTINGS OF PABLO PICASSO}

Cómo citar este artículo/Citation: Godoy C., I. (2013). "Suicidio en azul con negra mancha. Breve historia de un balazo en la pintura de Pablo Picasso". Arbor, 189 (764): a087. doi: http:// dx.doi.org/10.3989/arbor.2013.764n6010

Recibido: 9 junio 2013. Aceptado: 23 septiembre 2013.
Copyright: (C) 2013 CSIC. Este es un artículo de acceso abierto distribuido bajo los términos de la licencia Creative Commons Attribution-Non Commercial (by-nc) Spain 3.0.
RESUMEN: París 1901: por el amor de una mujer, se suicida de un balazo en la cabeza Carles Casagemas, amigo íntimo de juventud de Pablo Picasso. Este trágico suceso producirá un gran dolor en el artista, el cual, lo hará internarse en el tema de la muerte y elaborar su "duelo" apoyado en su pintura. El "hoyo a bala" en la sien de su amigo se desplazará simbólicamente a varios espacios de la vida del joven Picasso y devendrá en "vacío profundo" y "melancolía", permeando diferentes ámbitos dentro de la pintura de Picasso, dando comienzo a su mentado período azul.

PALABRAS CLAVES: Picasso; Casagemas; Gargallo; suicidio; duelo; melancolía; periodo azul.
ABSTRACT: Paris 1901: unrequited love drove Carles Casagemas, a close friend of Pablo Picasso's youth, to commit suicide by shooting himself in the head. This tragic event was a major blow to Picasso, causing him to dwell upon the subject of death and express his "mourning" through his paintings. The "bullet hole" in his friend's temple symbolically displaced several areas of the young Picasso's life and became a "deep vacuum" and "melancholy", permeating various areas in Picasso's paintings, and marking the start of his famous blue period.

KEYWORDS: Picasso; Casagemas; Gargallo; suicide; grief; melancholy; blue period.

"Hay que doblar cuidadosamente la realidad objetiva, como se dobla una sábana, y guardarla en un armario, de una vez para siempre". 


\section{EL ASUNTO CASAGEMAS}

Pablo Picasso y Carles Casagemas se conocieron en 1899 en Barcelona, en una taberna llamada Els Quatre Gats (Los cuatro gatos), que frecuentaban los artistas de la ciudad. Los dos tenían dieciocho años, aspiraban a ser pintores y a conquistar París. Compartieron estudio en la desaparecida calle Riera de Sant Joan, en el Barrio Gótico, y eran asiduos a los burdeles de la ciudad. Los dos amigos viajan a París en octubre de 1902, para visitar la Exposición Universal, donde Picasso exponía una obra titulada Últimos momentos. Se instalan en el estudio que les presta el artista catalán Isidro Nonell y unos días después, desde Barcelona, se les une Manuel Pallarès, compañero de estudios y de juerga de Picasso y Casagemas. Al poco andar, los tres pintores se habían hecho amigos entrañables de tres modelos muy codiciadas del medio, que posaban desnudas sin problema alguno: Germaine Gargallo, su media hermana Antoinette Fornerod y una amiga de ambas, Louise Lenoir, conocida como la pequeña Odette. Aunque de una manera más bien laxa, las parejas se distribuyeron de la siguiente manera: Casagemas con Germaine, Pallarès con Antoinette y Picasso con Odette. De las tres chicas, la que más destacaba por su descaro y belleza era sin dudas la multifacética Laure-Germaine Gargallo-Florentin-Pichot. Su nombre verdadero era Laure Gargallo y había tomado el apellido Florentin de su primer marido, el cual la había desposado siendo esta una adolecente, pasándose a llamar Laure Florentin, por lo cual cuando Picasso, Casagemas y Pallarés conocieron a las tres chicas, Laure, para arrancar de su pasado y hacerse un nombre en la noche parisina, había recién adoptado el nombre de Germaine y a su vez había recuperado su apellido de soltera: Gargallo. "Laure-Germaine" era una mujer de personalidad exuberante, muy atractiva, que aparte de bailarina y modelo ejerció como lavandera y costurera. Habrá que señalar igualmente, que fiel a su polifacética personalidad, Germaine al tiempo se volverá a casar, esta vez con el pintor catalán Ramón Pichot, del cual tomará una vez más su apellido, y lo unirá a su nombre original, pasándose a llamar, hasta su muerte, "Germaine Pichot".

Según consigna la crónica de la época, Casagemas, diletante más que otra cosa y con una pequeña fortuna personal, se habría enamorado irremediablemente de la modelo, Germaine Gargallo (Mailer, 1997, 65). Incisiva y cáustica, esta, no escatimaba en burlas a Casagemas, acusándolo incluso de poco hombre, por el amor contemplativo que este le profesaba. El asunto se puso peor al enamorarse perdidamente
Casagemas de Germaine y no ser correspondido. Innumerables veces y de diferentes formas Casagemas le pidió matrimonio, recibiendo solo burlas de la francesa. Habrá que consignar que en esa fecha Casagemas bebía excesivamente y era adicto a la morfina, tenía un serio problema de impotencia y para colmo de males, era bastante poco agraciado según señalan los retratos que le hizo Picasso en esa época. Según señala Mailer, Casagemas, comenzó a perder la cabeza por este amor imposible y a beber más de la cuenta. Germaine, noche tras noche, se fue poniendo más esquiva y sarcástica a los caprichos contemplativos de Carles, tratando por todo los medios de zafarse de su desequilibrado pretendiente. No tardó mucho en aburrirse definitivamente y buscar el abrazo de otros hombres. Fue en este escenario crítico en el cual Picasso conmina a Casagemas a que vuelvan a Barcelona y después a Málaga a pasar las fiestas de fin de año. Al repecto Mailer precisa: "Al compartir la cama con una mujer por vez primera y ser incapaz de nada más que "acariciarla" empezó a venirse abajo hasta tal punto que Picasso, cada vez más inquieto por la cordura de su amigo, decidió volver a Barcelona con él" $(1997,66)$.

A comienzos de 1901 Picasso se dirige a Madrid para trabajar como editor de la revista Arte Joven e invita a Casagemas a que lo acompañe. Sin embargo este desiste y promete volver con su familia a Barcelona. Obsesionado con Germaine, que es por el momento la dama de sus pensamientos (Cabanne, 1982, 118) le escribe en promedio dos cartas diarias pidiéndole matrimonio (Mailer, 68); al no tener respuesta de esta decide tomar subrepticiamente un tren a París. Con la angustia del enamorado llega a la ciudad de la luz el 16 de febrero de 1901, vestido con un impecable traje de terciopelo verde y una rosa roja en el ojal y en la misma estación de tren donde sus amigos y Germaine Gargallo lo esperaban, le pide a esta de rodillas y con la rosa roja en la mano, que sea su esposa. Ella una vez más se niega entre carcajadas. Casagemas herido ya de muerte por las palabras de su amada, consigue al menos que la noche siguiente, a modo de despedida, Germaine lo acompañe a cenar con todos sus amigos. A la hora del bajativo, mientras todos reían y bebían alegremente, con Germaine sentada a su lado, Casagemas tintineó el cristal de su fina copa de vino para llamar la atención de la mesa, se levantó ceremoniosamente y del bolsillo izquierdo de su chaqueta sacó una pistola, mientras aterrorizada Germaine se escabullía por debajo de la mesa para protegerse detrás de Pallarés. Este apenas alcanzó a desviar la dirección de la pistola antes de que Casagemas disparara a Germaine, gritándole a voz en grito: “Voilá 
pour toi!". Pallarés oyó una explosión ensordecedora y sintió cómo la frágil mano que se apoyaba en su hombro caía delicadamente al suelo. Casagemas, al contemplar el cuerpo inerte de su amada situó el cañón del arma en su sien derecha y sin cerrar los ojos gritó nuevamente: "Et voilá pour moi!" y se descerrajó un tiro, cayendo de bruces en los brazos de la Gargallo. A los minutos, "Germaine se incorporó y, llorando a lagrima viva abrazó y besó a Pallarés, mientras le rogaba que le perdonara por lo que había hecho: había representado su papel en la comedia a la perfección" (Palau i Fabre, 1980, 212).

Según consigna el parte de la policía de París, el domingo 17 de febrero de 1901, aproximadamente a las 9 PM, Carlos Casagemas se suicidó en L'Hippodrome Café, 128 Boulevard de Clichy, en París, Francia, al pegarse un tiro en la sien derecha. Tenía 20 años de edad. Picasso se encontraba en Madrid y se enteró a los pocos días de la muerte de su amigo. La noticia conmovió a toda su generación, pero en especial a él. Según le confesó a uno de sus biógrafos, Pierre Daix, muchos años después, "Me puse a pensar pintar en azul al pensar en la muerte de Casagemas" (cit. en Leal-Piot-Bernadac: 2000, 51).

\section{RETRATOS PARA UN SUICIDIO}

El ciclo de Casagemas alude a una profundización psicológica de Picasso ante la muerte, en la densidad de un mundo subterráneo (Golding, 1994, 214), paralelo al del sufrimiento, la demencia, el patetismo y la pobreza que presenció en el París de comienzos del siglo XX (Podoksik, 1996, 32). El pintor malagueño habría reafirmado la condición testimonial de su obra, al señalarle en su momento a una de sus amantes que pintaba al igual que otros escriben su autobiografía: "Mis telas, acabadas o no, son las páginas de mi diario" (Gilot, 1965). Ciertamente, las obras de Picasso sobre la muerte de Casagemas no solo inauguran el período azul del pintor malagueño y el valor taumatúrgico de estas, en cuanto a exorcizar el espectro del suicidio de Casagemas, del cual se siente en cierta manera responsable (Battistini, 2000, 26), sino que también le permiten elaborar el "duelo" y la consiguiente "melancolía", imprescindibles para dar curso a la profunda tristeza que lo embarga: "En el duelo, lloramos a los muertos, en la melancolía, morimos con ellos" (Leader, 2011, 15). Lo particular de los retratos pintados por Picasso del rostro del difunto Casagemas, radica en que el pintor malagueño los realiza de memoria, a partir del relato recibido, pues estaba en Madrid cuando Casagemas se suicida. Picasso no asiste a las exequias fúnebres, ya sea por pena, por culpa, o simplemente como señala Foucault respecto al suicidio, por la "perplejidad" $(1987,168)$ que ocasiona. Por lo tanto no vio jamás a su amigo muerto. En mayo de ese mismo año, dos meses después del suicidio, regresa a París para preparar su primera exposición en la galería de Ambroise Vollard y se instala nada menos que en el estudio de Pallarés, en el 130 del Boulevard de Clichy, donde Casagemas había pasado su última noche.

Al poco tiempo de llegar a París no tuvo reparo alguno en entablar una relación amorosa con Germaine, para sorpresa de todos sus amigos, la cual ya a esas alturas se encamaba con el escultor catalán Manuel Hugué, que había estado en la mesa de Casagemas la noche de los disparos (Mailer, 75). El 24 de junio de 1901 en la Galeria Vollard, a casi cuatro meses del suicidio de Casagemas, Picasso inaugura su primera exposición, que será todo un éxito y le hará ganar bastante dinero, el cual gastará junto a la Gargallo con total desparpajo, en noches de lujuria empapadas en absenta. Es entonces, después de meses de haber ocurrido el suicidio de Casagemas que este aparecerá en la lúbrica conciencia de Picasso, para recordarle su triste destino. Picasso comienza su mentado "período azul" con el suicidio de Casagemas, pero por cierto también, bajo las sábanas de la cama de la Gargallo. Una de las formas de entender este tórrido romance, es lo que nos explica Freud en Duelo y melancolía, en cuanto a que la melancolía -a diferencia del duelo-, radica el "objeto de su pérdida" en el inconsciente, interrogándose a su vez por "lo perdido" $(1917,3)$. Esta pérdida, según Freud, también arrastra "acusaciones contra el yo", por lo tanto la escandalosa escenificación del romance con la Gargallo sería una más de las etapas de la "melancolía picassiana" por la muerte de su amigo, en la cual asumirá la abyecta figura de lo "indigno, egoísta, deshonesto, despreciable y moralmente condenable" (3-4). También habrá que considerar, sobre este idilio, que en lo "prohibido" radica la razón del erotismo, tal como señala Bataille (1985), y en la transgresión del interdicto su pasión: "si la unión de los dos amantes es el efecto de la pasión, esta apela a la muerte, al deseo de asesinato o de suicidio, lo que designa a la pasión es un halo de muerte" (35).

El asunto se complejiza más aún con lo que señala Norman Mailer, en cuanto a que no es de extrañar que Picasso y Casagemas hayan frecuentado esa tierra de nadie que existe entre la heterosexualidad y la homosexualidad, más allá de los patrones andaluces de machismo con que cargaba el pintor; sin embargo, sostiene el escritor norteamericano, que una de las 
razones principales de Picasso para seducir a la Gargallo tenía que ver con el hecho de conocer carnalmente a la viuda nominal de su amigo, de encontrar a Casagemas en el deseo de este: en el cuerpo de la amada, “...aquello era también un acto de amor; puede que incluso haya sido una especie de expiación, fornicar con Germaine era invocar a Casagemas más que disiparlo" (Mailer, 1997, 77).

Señalaba Apollinaire que "Picasso estudia un objeto como un cirujano disecciona un cadáver" (cit. en
La muerte de Casagemas (Lámina 1)- que el pintor malagueño debió de asistir a esta exposición, que fue un suceso no solo en París sino en toda Europa. El hecho es que Picasso va a pintar esta primera obra, recién un mes después de inaugurada su exposición con Vollard, cinco meses después de la muerte de Casagemas. En este contexto se hace relevante el tiempo transcurrido desde el fatal episodio a la realización de este primer retrato, por cuanto podemos inferir que en Picasso operó una decantación del modelo, esto es, una re-contextualización de lo ocurrido, una sín-

Lámina 1. La Muerte de Casagemas, Pablo Picasso. Óleo sobre tela. 1901. Musée National Picasso de Paris.

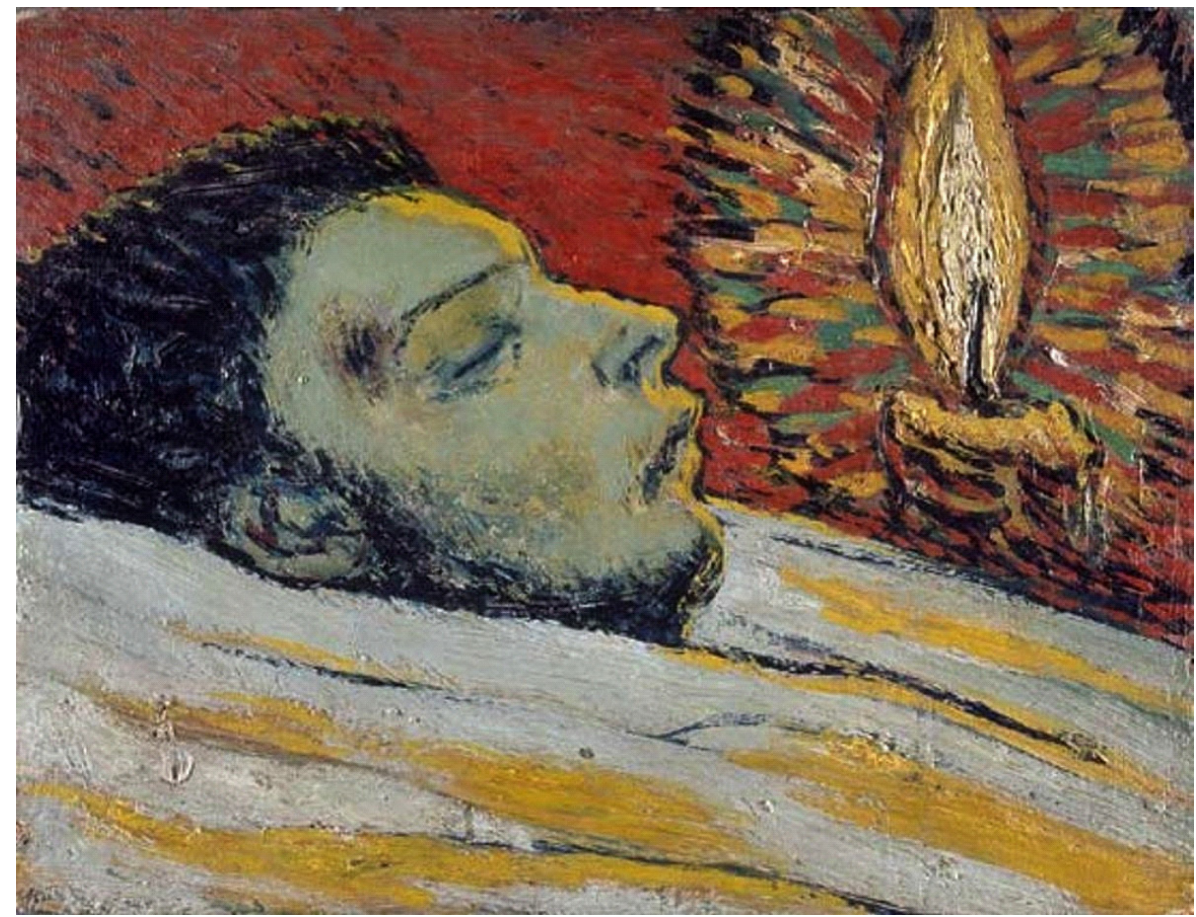

Cirlot, 2007, 48). Pues bien, el cadáver de Casagemas debió de haberse constituido en Picasso -como señala Kristeva-, en aquella "mierda", incomoda mezcla de desecho e impureza, que "apenas soporta la vida con esfuerzo" $(2006,10)$. Brutal, por decir lo menos, es el primer retrato que pinta Picasso del rostro de su amigo Casagemas muerto. Indudablemente, como lo han visto múltiples autores, este primer retrato de Casagemas tiene la impronta de Van Gogh. Hacía 10 años que Vincent había muerto y a los pocos días del suicidio de Casagemas, en marzo de 1901, se inauguraba en París, en la Galería Bernheim-Jeune, la retrospectiva de Van Gogh más famosa de todos los tiempos (Beujean, 2005, 90). Es indudable $-y$ así lo atestigua tesis a modo de epitafio del recuerdo de su amigo, unido a todos los acontecimiento que rodearon su muerte. Casagemas es Van Gogh inmolado en su pasión, así lo atestigua la coincidencia en sus destinos, así lo atestigua la manera de esta pintura con fuertes y gruesas pinceladas que hacen saltar los azules, rojos y negros con los amarillos de la luz de la vela, otorgándole al rostro del difunto un dramatismo sin igual; sin embargo hay un algo más terrible en esta pieza, otorgándole protagonismo, no a la muerte en sí, sino más bien al detalle por el cual esta acaeció: un "hoyo negro" a causa de la bala, una mancha brutal e ingrata pende sobre la sien derecha de Casagemas y vacía su figura. Precisa Bataille respecto al vacío de la muerte: 
"ese vacío se abre en un punto determinado. Es, por ejemplo, la muerte la que lo abre: es el cadáver en el interior del cual la muerte introduce la ausencia, es la podredumbre vinculada a esa ausencia" $(1985,85)$.

Es un extraño fragmento en la historia de la pintura lo que pinta Picasso. Esta herida en la sien de Casagemas de seguro está avalada por las llagas del Cristo muerto de Messina que cuelga en los muros del Museo del Prado. Sin embargo, aquí sobre la carne no sobreviene la crística llaga, la roja sangre brilla por su ausencia y todo es azul y negro en este hoyo de bala. La carnes devienen gélidas, definitivamente la podredumbre como el vacío acontecen pálidos en Picasso. Sin embargo otro hoyo devendrá de esta primera obra, una "vagina incandescente" (Palau i Fabré, 1980, 210), a modo de vela, iluminará el cadáver del suicida. A su vez, en esta misma línea, Mailer señalará una "vagina-hoyo" de doble condición, en la cual la polaridad aflicción y concupiscencia se encuentran, tanto en la vagina materna dadora de vida y de luz, como así en la de la amante destructora de la misma: "Picasso no encuentra obstáculos para dar a entender que no solo venimos al mundo a través de la vagina, sino que también podemos ser destruidos por una, para acabar siendo llorados por otra" (Mailer, 1997, 85).

El asunto de la Gargallo adquiere aquí particular relevancia, por cuanto Picasso inexplicablemente modificará el primer retrato de La Muerte de Casagemas y pintará otro sobre cartón, en el cual borrará el hoyo a bala en la sien de su amigo y titulará Casagemas en su ataúd (Lámina 2). Señala Bataille (2000), que es rasgo humano procurar alcanzar el punto más lejano del "terreno fúnebre" y que: "por todas partes borramos las huellas, los signos, los símbolos de la muerte, a costa de incesantes esfuerzos. Llegamos a borrar incluso, si es posible, las huellas y los signos de esos esfuerzos" (99). Si en La Muerte de Casagemas Picasso hace ostentación del detalle significativo, de la evidencia brutal de lo ocurrido, del "hoyo" en la sien de Casagemas que grita el nombre de Gargallo a los cuatro vientos, en Casagemas en su ataúd Picasso silencia la evidencia suicida en el cadáver, -cubriendo con pintura el hoyo a bala-, para dejar reposar a su amigo en la fría muerte como uno más. El azul cadáver impertérrito oculta con su gelidez toda evidencia de lo ocurrido y, por cierto, el nombre de la causante. El "hoyo a bala" en la sien es "mácula" -como señala Lipovedsky respecto al suicidio-, que delata y condena el "acto indigno" (2012: 84) del inmolado. Ya no hay aquí vela vaginal ni el agujero sexual o criminal; el detalle ha sido hipostasiado por el frío y neutro velo de la muerte. El homenaje se hace solemne y general.
Pero también el "hoyo" es Germaine, es su presencia en el fatal destino del amante desencantado, es la huella permanente que recuerda a Picasso que está durmiendo con la causante de la muerte de su amigo. Picasso no querrá más imaginar a Germaine -su ferviente amante-, como un gran agujero en la frente de su amigo; sin embargo este "hoyo" no desaparecerá sino que transmutará y al tiempo Picasso lo llevará a nuevas disposiciones dentro de otras obras en las cuales volverá a tratar el tema de la muerte de Casagemas. Precisa Mailer, "Picasso está a punto de entrar en la depresión más oscura y larga de su vida" (86), pero agregado a esto, también a uno de los periodos más fértiles de su pintura.

Lámina 2. Casagemas en su ataúd, Pablo Picasso. Óleo sobre cartón. 1901. Colección privada.

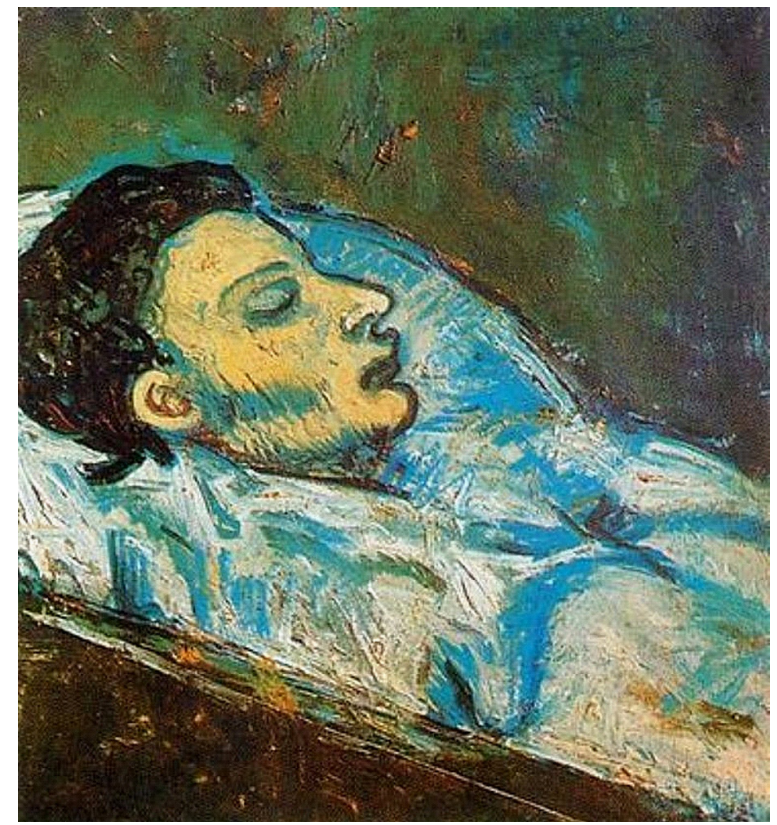

¿Por qué Picasso pinta una segunda versión, sin el agujero de bala en la sien de su amigo? ¿Qué quiere ocultar? ¿Lo habrá hecho por Germaine Gargallo o simplemente por un profundo sentimiento de culpa? ¿A dónde se fue aquel hoyo negro?

\section{CASAGEMAS QUE ESTÁS EN LOS CIELOS}

Picasso se hace amante de Germaine Gargallo cuando el cuerpo de su amigo "aún estaba tibio", y quizá por eso tapa el hoyo a bala con una palidez maldita en la versión Casagemas en el ataúd. Señala George 
Bataille que: "hay, necesariamente vinculado al momento de la voluptuosidad, una ruptura menor evocadora de la muerte: en contrapartida, la evocación de la muerte puede entrar en la puesta en marcha de los espasmos voluptuosos" (1985: 149). Aún así, hay un "hoyo" sin tapar, un hoyo por el cual respira y se fuga, esquivando la voluptuosidad de Picasso, el drama de Casagemas. Picasso sabe que ese hoyo es el del sentido de la vida y el vacío que deja la muerte, de la cual es tributaria la pintura desde siempre.

Picasso pintará una nueva obra en torno al suicidio de su amigo, titulada Evocación, el entierro de Casagemas (lámina 3), en la cual desplegará el valor taumatúrgico de la pintura, regalándole a su amigo un nuevo funeral. De la sien derecha tapada por Picasso en Casagemas en el ataúd, volverá a emerger debajo del pálido empaste azul, como una maldición, el "negro hoyo" del balazo, pero esta vez de diferente forma. Allí, en la oquedad donde todo era oscuridad y deyección mortuoria, cual mago, Picasso hará aparecer de su paleta un cielo prostibulario donde coloca a su amigo, un cielo amable, en directa escala a la morfina, a la absenta y a los lupanares donde los dos amigos desarrollaron su amistad. Como señala Carlos Gurméndez, "el deseo es el cuerpo que se hace pura materialidad ansiosa..." (1986: 227), y es justamente en esa pura materialidad pictórica donde Picasso, para evacuar el vacío de la ausencia de su amigo, le otorga otra vida, poniéndolo en medio del deseo y el placer. No hay que olvidar que este asunto de la "trascendencia del cadáver" no debió ser menor para la familia de Casagemas, en cuanto a que los suicidas "no se van al cielo", precisamente. El suicidio ante todo es un crimen social que aparece como "un signo de cobardía frente a las dificultades de la vida". Hay que entender que dentro de los valores emergentes de la modernidad, aun permanecía la acendrada creencia de que "el hombre que pone fin a sus días no es solo inmoral porque se desentiende de sus obligaciones hacia la colectividad sino porque se sustrae a un deber individual absoluto" (Lipovetsky, 1994, 85). Será justamente en este contexto de vacío, del no lugar del cadáver del suicida, donde las almas vagan en pena, donde Picasso le construirá y le regalará a su amigo un cielo puto, "blasfemo" (Golding, 214), plagado de meretrices, hecho para fornicar permanentemente.

En Evocación (lámina 3), el cuerpo de Casagemas amortajado de blanco, listo para ser depositado en un mausoleo, yace como dormido en el suelo, mientras es llorado por múltiples mujeres de negro. En un plano superior, Casagemas en su semental blanco, se eleva al cielo con los brazos en cruz como un Cristo,
Lámina 3. Evocación (El entierro de Casagemas), Pablo Picasso. Óleo sobre tela. 1901.

Museé d'art Moderne de la Ville de Paris.

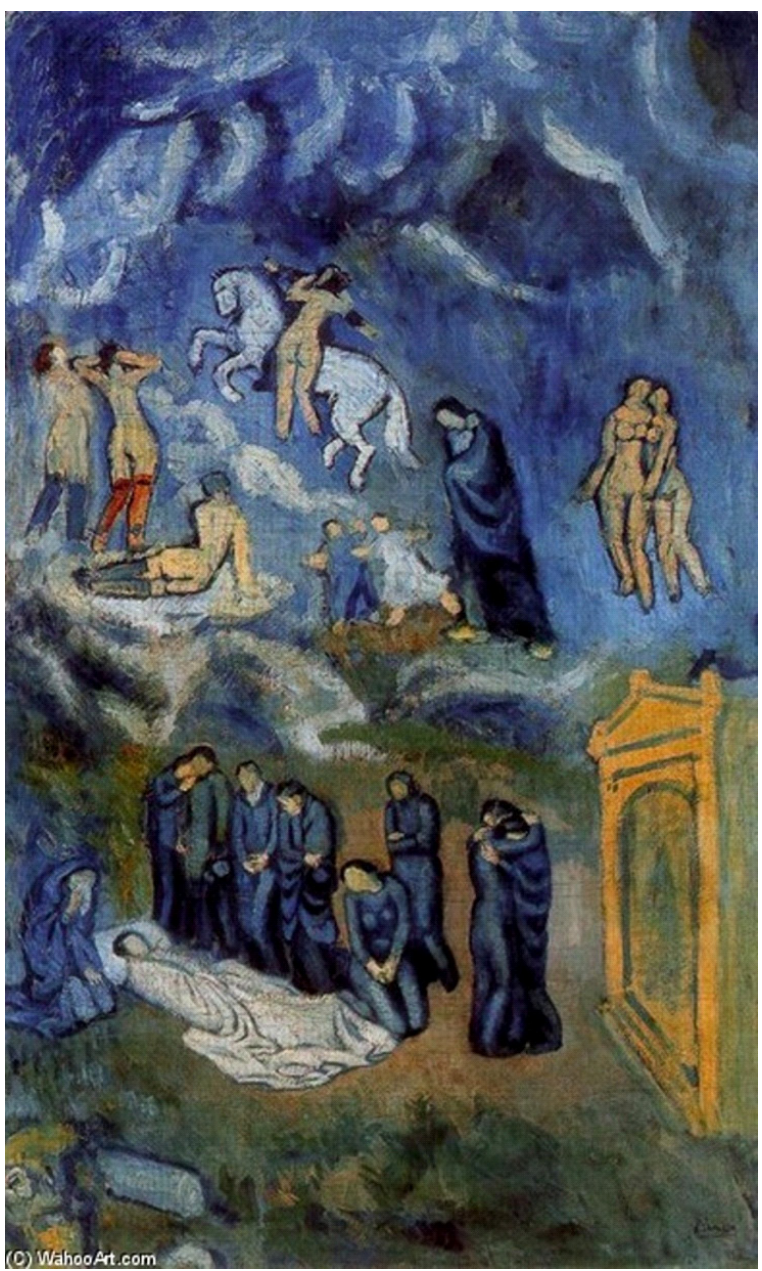

mientras de su cuello pende Gargallo desnuda. Las putas, todas dispuestas, esperan al suicida en el único cielo posible, el del placer eterno. El "hoyo" se ha consumado en su trascendencia, iluminándose con otros sentidos. Picasso ha ritualizado nuevamente la muerte de su amigo y lo ha llevado donde los suyos, a una nueva vida de voluptuosidad. Más que un "hoyo negro", Evocación es un nicho azul donde Picasso pone a Casagemas, para lo cual ha vaciado de contenidos el cielo, para darle a su amigo otra mejor vida. A propósito del duelo, señala Dorian Leader: "Matar a los muertos es una forma de aflojar los lazos con ellos y de situarlos en un espacio diferente, simbólico. Tal vez entonces se vuelva posible comenzar a forjar nuevos lazos con los vivos" $(2011,113)$. ¿Gesto de amor? ¿De justicia? ¿De culpabilidad? 
En enero de 1903 Picasso volvió a Barcelona. En la primavera comenzó el cuadro La vida (Lámina 4), uno de los mayores y más complejos lienzos de su época azul, considerado su trabajo más importante de estos años, obra de un simbolismo inusualmente oscuro. Esta pieza nos muestra un nuevo desplazamiento del hoyo a bala en la sien de Casagemas y tiene justamente como protagonistas a su amigo muerto, esta vez junto a la Gargallo. Picasso ha pintado La vida contraponiendo dos grandes temas de la pintura: el de la pareja desnuda, de pie y enlazada, y el de la majestuosa maternidad pobre, cubierta con un manto y los pies desnudos. Picasso pinta al hombre de la pareja con particulares rasgos: "el impotente Casagemas. Un varón capaz de amar hasta el extremo de quitarse la vida, pero negado por la naturaleza para engendrar hijos en cuerpo de mujer" (De la Puente, 1991, 199), junto a su "amada" Germaine. Dos personalidades tiernas y delicadas que se abrazan frágilmente. Es un abrazo triste también, donde la desnudes no preludia pasión alguna. El azul invade la escena y presagia el trágico fin de los amantes. Casagemas con un tapa rabo es un Cristo viviendo los últimos minutos de su martirio. Al frente de la pareja está la figura de la maternidad -icono sistematizado por Picasso durante toda su vida-, con un niño que plácidamente duerme en sus brazos, inocente de lo que el destino le traerá. Con su perfil severo y estatuario la mujer-madre que aquí aparece como especie de retrato del dolor, se contrapone a la figura de los amantes -y aquí lo trágico de la representación-, figura que debieran representar la felicidad. En La Vida, la mujer desnuda se apoya ensimismada y pensativa en un hombro de él, mientras Casagemas, a través de un forzado gesto con la mano, señala lo que han sido y serán: una niñez necesitada de cobijo y de regazos y una madurez camino de la ancianidad. La representación hace referencia de esta manera a la antigua vanitas cristiana, aquella que se pintaba con el título de las tres edades y que incluían la niñez y la adultez, a las cuales se añadía la muerte o la vejez, mostrando el espantable pellejo de su decadencia corporal. Paradójicamente las miradas de los personajes "no se encuentran y se pierden en un vacio desolador" (Warncke, 2002: 103). Picasso ha desplegado esta obra en el contexto de un taller de pintor, donde otros dos cuadros en un segundo plano, conforman un coro doloroso de figuras que preludian el trágico destino del suicida. Un primer cuadro de este dramático fondo evoca la tristeza de la soledad y el otro, encima de él, el consuelo del calor humano.

Picasso, según consignan sus biógrafos, realizó cuatro bocetos preparatorios para el cuadro La vida, va- riando la composición de las figuras al menos dos veces; cabe destacar que la figura masculina, que empezó siendo un autorretrato -he aquí lo relevante-, acabó siendo una representación de su amigo Carles Casagemas. Señala Pellicer (1981) que "Aquí no hay una lectura argumental del tema. No es, como diría una lectura superficial, la escena de los amantes sorprendidos por la mujer legítima. Es más bien una confrontación entre el romanticismo que no piensa en el futuro y la realidad gravosa y dura. (86). Será por lo tanto, en este sentido, que se habrá de pesquisar esta operación llevada a cabo por Picasso sobre la apariencia del protagonista.

Fenomenológicamente el "encubrimiento", el "recubrimiento" y el "descubrimiento" en estas obras sobre Casagemas serán tres categorías de un síntoma reiterativo y de una operativa pertinaz en procura de ritualizar el duelo y la melancolía, que a su vez serán el "llenado ante el vacío de la muerte", o "la lucha ante el espanto del sinsentido frente a la dramática apa-

Lámina 4. La vida, Pablo Picasso. Óleo sobre tela. 1903. Cleveland Museum of Art.

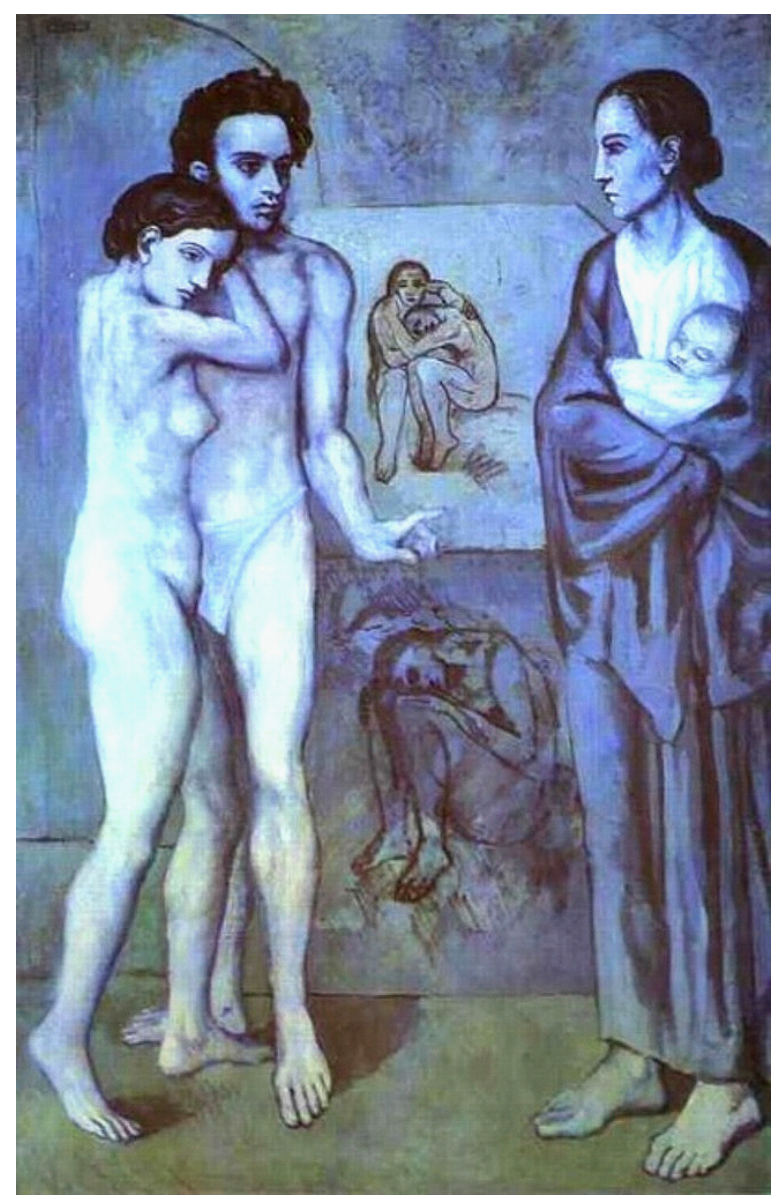


riencia del cadáver de su amigo". En este dirección hay que precisar, como señala Donald Winnicot, que "el vacío es un requisito previo del anhelo de recibir algo dentro de sí", es decir que el vacío primario significa, simplemente un, "antes de empezar a llenarse" (Winnicot, 1974,119). Será por lo tanto en esta trayectoria -la del "hoyo a bala" en la sien de Casagemas-, que Picasso se guiará para llenar de sentido, tanto físico como síquico, el vacío producido por el suicida. Al igual que el síntoma o la apariencia en la fenomenología de Heidegger, Sigmund Freud encontrará en "lo ominoso"1 (heimlich) -que también será traducido como "lo siniestro"-, aquel objeto familiar que esconde algo, donde la verdad se encuentra velada, y que al aparecer cambia de cualidad, convirtiéndose en algo terrorífico (Cattaneo, 2011, 4). Será justamente bajo aquella "apariencia" en la obra La vida, donde habitará lo clandestino en Picasso como "doble". Ominoso en grado supremo -señalará Freud-, es lo que refiere a la intimidad con la muerte, los cadáveres y el retorno de estos a la vida. Es justamente en este escenario donde la figura del doble ${ }^{2}$ adquiere a su vez un "doble sentido". El "hoyo a bala" se ha desplazado una vez más y ha devenido como escena y rostro -nada menos que del propio pintor-, que esta vez, a diferencia del pálido pigmento azul que cubrió el balazo en Casagemas en su ataúd, ha sido cubierto, en un segundo movimiento, con el rostro del propio Casagemas, instaurando "sobre" el rostro de Picasso y "bajo" el rostro del suicida la figura de un "doble", de un "uno mismo que es otro". Paradójicamente y de igual forma, La vida está pintada sobre otra famosa obra de Picasso, que se buscó durante mucho tiempo y que se creía pérdida: Últimos momentos. Fue justamente esta obra la que Picasso había presentado a la Exposición Universal de 1900 y que lo llevó a viajar a París por primera vez con su amigo, dando comienzo al trágico affair Gargallo-Casagemas. Cabe precisar qué Últimos momentos representaba curiosamente a un "moribundo en su lecho de muerte" (Warncke, 2002,108). Una vez más "lo que cubre descubre", como una operación semi-ciega del artista en cuanto se desplaza precariamente por el vacío de la muerte y cubre subrepticiamente de nuevos sentidos a personajes y situaciones.

\section{TRES HOYOS PARA UNA BALA (CONCLUSIÓN)}

Picasso no solo era consciente de los hoyos, agujeros y concavidades en su obra, sino que, además, conceptualizó sobre ellos. Brassaï (2002) fotografiará la escultura Cabeza de Muerto (lámina 5) de Picasso en septiembre de 1943, y señalará con admiración: “Una obra sobrecogedora. Es más una cabeza monumental petrificada con las órbitas vacías, la nariz carcomida, los labios borrados, que un esqueleto descarnado y gesticulante. Es como un bloque de piedra errante, comido de cavidades" (77). Picasso siempre mostró fascinación por los agujeros, puntualizando que "el arte es el lenguaje de los signos". En una conversación que tendrá el mismo Picasso con Brassaï en 1946 y a propósito de unas fotos de grafitis callejeros, el malagueño le comentará: "Fíjese en esos ojos. Son hoyos profundos cavados en la pared. Pero algunos parecen combados, como si estuvieran en relieve. ¿De dónde sale esto? No es un efecto óptico; se ve perfectamente que son agujeros. Lo que sabemos influye en nuestra visión". (245).

Un balazo es homologable a la expresión «pegarse un tiro", cuyo resultado es un "hoyo de bala". Un agujero tiene algo traslúcido que no tiene un hoyo. Un agujero deja pasar algo, al menos la mirada a través de él. El agujero, por lo general, sorprende al unir, ya sea por intención o accidente, dos realidades colindantes; por el agujero pasa la luz o al menos rebota esta en su

Lámina 5. Cabeza de muerto, Pablo Picasso. Piedra. 1943.

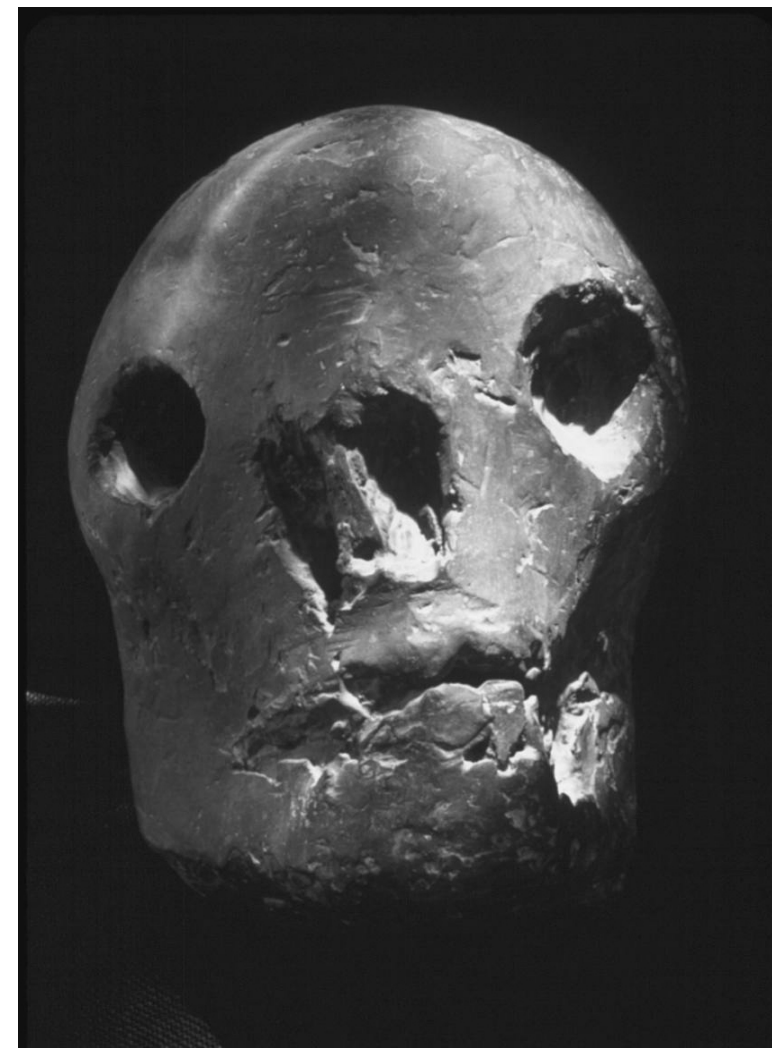


"fondo". El hoyo, sin embargo, es inescrutable y abismal, porque es ciego. El hoyo es pura oquedad y lleva en sí la fosa mortuoria, la oscuridad de la cavidad que ciega la mirada en lo más profundo de sí. Como señala Edmund Burke (2010), para que en general una cosa sea muy terrible es imprescindible que sea oscura (87). La asociación de lo oscuro con lo terrible apunta a que en la profunda oscuridad se pierde toda referencialidad, quedando el sujeto a la deriva: "podemos caernos a un precipicio al primer paso que demos" (180). El hoyo es oscuridad y también negrura y las dos condiciones son dolorosas naturalmente (181). Es fuerte y dolorosa la palabra agujero, pero aún más la palabra hoyo, por cuanto esta contiene algo vil y también soez, sobre todo cuando refiere a un "hoyo de bala en la sien de un suicida». Hay algo insondable en las expresiones "hoyo de bala" y "suicida", que se conjugan dramáticamente con las palabras "oscuridad" y "negrura". En esta conjunción se oculta lo atroz y los sentidos se fugan indefectiblemente rumbo a la nada. Es justamente este "vacío de la muerte", homologable a un hoyo aterrador donde habitan la oscuridad y negrura, lo que determina la recurrencia melancólica de Picasso de pintar a su amigo una y otra vez. Es pertinente aquí la reflexión de Leader, que afirma que: "La persona amada perdida se convierte en un hueco, un vacío siempre presente a cuyo apego el melancólico no puede renunciar" (Leader, 177), a no ser que ritualice e incorpore al muerto en sí mismo a través de su obra. El balazo o el "hoyo a (o de) bala" en la sien de Casagemas produce un vacío profundo e insondable que va más allá del cuerpo del suicida, produciendo una macabra ausencia: "es el cadáver en el interior del cual la muerte introduce la ausencia, es la podredumbre vinculada a esa ausencia" (Bataille: 85). Será entonces, desde este dramático "vacío", que Picasso elaborará su "duelo" -llorando a su amigo-, con la consiguiente "melancolía" -de morir con él-, dando comienzo a su mentado período azul.

Picasso era consciente de los "desplazamientos" en su pintura que cubren y descubren (Malraux, 1974) en pos de un sentido, como así, que no necesariamente lo que comenzaba terminaría según lo esperado, importando poco la voluntad del artista (Kanweiler, 1955). El arte es para el pintor malagueño, un proceso de muertes acumuladas, una suma de "destrucción" y no un simple acto de "creación", y el arte es el camino seguido por el cerebro en la materialización de un anhelo. Podemos reflexionar que Picasso ve la muerte como un principio de desplazamiento, donde nada se pierde, donde "el rojo que he quitado de una parte se encuentra en alguna otra parte" (Zervos, 1935, 173).
Será entonces, como de esta operación nostálgica del artista malagueño sobre la "herida de muerte" en la sien de Casagemas, se derivarán tres "hoyos simbólicos" o "desplazamientos del vacío" en las obras respecto a este episodio, los que remitirán a su vez, a tres cuerpos y contextos diferentes, en los que Picasso procurará construir un sentido para la trágica desaparición de su amigo.

El primer desplazamiento se dirigirá al espacio de la amistad o philía de Picasso y Casagemas, y se referirá al vacío dejado por la pérdida brutal del vínculo, el que será plasmado magistralmente en toda la serie inspirada en el suicidio de su amigo. Pero será en Muerte de Casagemas (lámina 1,) específicamente, donde el "hoyo a bala" en el retrato del cadáver del suicida atestiguará la brutal pérdida. Este "hoyo negro" tomará cuerpo y se desplazará virulentamente en múltiples imaginarios dentro de la obra del pintor malagueño. La muerte devorará los sueños de juventud y la "complicidad" de los amigos y pondrá fin a la juventud aventurera de Picasso, consolidándolo en una pintura azul, sombría y trágica (La comida del ciego, La celestina, Los pobres a la orilla del mar, El viejo guitarrista ciego, El viejo judío, etc.).

Un segundo movimiento estará dirigido al eros, entendido este como aquel lugar de la consumación carnal del deseo. Este lugar no es otro que el del deseo de su amigo, personificado en la figura de la Gargallo. En su ardorosa relación post-morten con Germaine, Picasso unirá su pasión y tristeza en torno a la figura de la "muerte" de su amigo, entendida esta como "continuidad" en la cual se funden uno con el otro en el acto sexual, al modo de una pequeña muerte (petit morte), una pequeña muerte evocadora de la gran muerte (Bataille). Será en este espacio, ante el vacío producido por la ausencia del "pretendiente" Casagemas y su incapacidad en sus afanes amorosos, desde donde emergerá un brioso Picasso "amante", dispuesto a reivindicar, plasmar y consumar con la Gargallo, lo que su amigo no había logrado. Sin duda, la obra que mejor encarna este desplazamiento es Casagemas en el ataúd (lámina 2), segunda versión sobre el cadáver del suicida, en donde ha desaparecido la huella del balazo en la sien, y su posible causa.

En tercer lugar, el hoyo a bala se desliza en esta trama simbólica, aunando los dos espacios anteriores para conformar lo "sagrado", entendido como aquel espacio de sentido - tanto físico como psíquico-, donde es posible la vinculación con los muertos. El verbo sacrare significaba en el pasado "consagrar" y remitía a una operación previa, a través de la cual se ponía en 
valor trascendente una cosa o lugar. Para Mircea Eliade (1981) lo sagrado es aquella experiencia que refiere a la fundación de mundo desde donde surge desde lo trivial lo excepcional ${ }^{3}$ (hierofania). En este sentido, será justamente desde la pintura y su capacidad taumatúrgica que Picasso hará del cadáver de su amigo un "cuerpo de trascendencia", en donde lo excepcional ritualice y a la vez sea ritualizado. A este respecto resultan clarificadoras las obras: Evocación, el entierro de Casagemas, en la cual Picasso le construye en el cielo un altar a su amigo muerto y La vida, en don- de el pintor malagueño trae a la vida por última vez a su amigo, para despedirse de él. Son iluminadoras aquí las palabras de Bataille (1985), que afirman que el hombre solo puede superar lo que le horroriza si es que puede mirarlo cara a cara. En lo que concierne a Picasso y su relación con la vida y muerte de Casagemas, es posible plantear que será bajo el gobierno del duelo y la melancolía, que, más allá del período azul, inclusive, mirará cara a cara la muerte y exorcizará una y otra vez el "vacío" producido por la pérdida de su gran amigo.

\section{NOTAS}

1 “Lo más interesante para nosotros es que la palabrita heimlich, entre los múltiples matices de su significado, muestra también uno en que coincide con su opuesta unheimlich. Por consiguiente, lo heimlich deviene unheimlich. En general, quedamos advertidos de que esta palabra heimlich no es unívoca, sino que pertenece a dos círculos de representaciones que, sin ser opuestos, son ajenos entre sí: el de lo familiar y agradable, y el de lo clandestino, lo que se mantiene oculto... Entonces, heimlich es una palabra que ha desarrollado su significado siguiendo una ambivalencia hasta coincidir al fin con su opuesto, unheimlich. De algún modo, unheimlich es una variedad de heimlich" (Freud, 2000, 224).

2 "La presencia de «dobles» en todas sus gradaciones y plasmaciones, vale decir, la aparición de personas que por su idéntico aspecto deben considerarse idénticas; el acrecentamiento de esta circunstancia por el salto de procesos anímicos de una de estas personas a la otra - lo que llamaríamos telepatía-, de suerte que una es co-poseedora del saber, el sentir y el vivenciar de la otra; la identificación con otra persona hasta el punto de equivocarse sobre el propio yo o situar el yo ajeno en el lugar del propio -o sea, duplicación, división, permutación del yo-, y, por último, el permanente retorno de lo igual, la repetición de los mismos rasgos faciales, caracteres, destinos, hechos criminales, y hasta de los nombres a lo largo de varias generaciones sucesivas (Freud, 2000, 234).

3 "Nunca se insistirá lo bastante sobre la paradoja que constituye toda hierofanía, incluso la más elemental. Al manifestar lo sagrado, un objeto cualquiera se convierte en otra cosa sin dejar de ser él mismo, pues continúa participando del medio cósmico circundante" (Eliade, 1981, 10).

\section{BIBLIOGRAFÍA}

Bataille, G. (1985). El erotismo. Barcelona: Tusquets editores.

Bataille, G. (2000). La literatura y el mal. Buenos Aires: Ed. El Aleph.

Battistini, M. (2000). Picasso. Barcelona: ed. Electa.

Bujean, D. (2005). Van Gogh. Barcelona: ed. Tandem Verlag $\mathrm{GmbH}$.
Brassaï, G. (2002). Conversaciones con Picasso. México D.F.: ed. Fondo de Cultura Económica.

Cabanne, P. (1982). El siglo de Picasso. Vol. 1, 1881-1937 El nacimiento del cubismo. Madrid: Ministerio de Cultura, D. L.

Cattaneo Rodríguez, G. (2011). "Lo ominoso y el artefacto de la mirada". Revista Affectio Societatis, Vol. 8, № 15, pp. 1-18, diciembre, art. \# 16, Medellín,
Departamento de Psicoanálisis, Universidad de Antioquia.

Cirici i Pellicer, A. (1981). Picasso. Su vida y su obra. Madrid: N. Editorial.

Cirlot, L. (2007). Primeras vanguardias artísticas: textos y documentos. La Plata: ed. Terramar.

De la Puente, J. (1991). La pintura: de Goya a las últimas tendencias. Barcelona: Ca- 
rroggio de Ediciones S.A., Tomo 6 de la Historia del Arte.

Eliade, M. (1981) Lo sagrado y lo profano. Madrid: Guadarrama/Punto Omega.

Fermigier, A. (1969). Picasso. Le Livre de Poche. Série Art. Librairie Génerale Française, París, Francia.

Foucault, M. (1977). Historia de la sexualidad. 1-Voluntad de saber. México D.F.: Siglo XXI editores.

Freud, S. (2000). "Lo ominoso". En Freud, S., (Trabajo original publicado en 1919), Obras completas, Vol. XVII, p. 217-251. Buenos Aires: Argentina Amorrortu ediciones.

Gilot, F. (1965). Vivre avec Picasso. París: Calmann-Lévy.

Golding, J. (1994). Visiones de la modernidad. Berkeley: University of California Press.
Gurmendez, C. (1986). Tratado de las pasiones. México D.F.: Fondo de cultura económica.

Kahnweiler, D. H. (1955). "Entretiens avec Picasso au sujet des Femmes d'Alger", Aujourd'hui Magazine. Extraído de Edición de Bernadac, M. L. y Michael, A. (1998), Picasso. Propos sur l'art. París: Gallimard.

Kristeva, J. (2006). Poderes de la perversión, ensayo sobre Louis Ferdinand Celine. Madrid: Siglo XXI editores.

Leader, D. (2011). La moda negra. Duelo, melancolía y depresión. Madrid: Editorial Sexto Piso España, S.L.

Leal, B.; Piot, C.; Bernadac, M. L. (2000). Picasso total. Barcelona: ed. Polígrafa.

Lipovetsky, G. (1994). El crepúsculo del deber. Barcelona: Editorial Anagrama.
Mailer, N. (1997). Picasso retrato del artista joven. Madrid: ed. Santillana. S.A. (Alfaguara).

Malraux, A. (1974). La tête d'obsidienne. París: Gallimard.

Palau i Fabre, J. (1980). Picasso vivent. Barcelona: ed. Polígrafa.

Podoksik, A. (1996). Pablo Picasso: El Ojo Creativo (Desde 1881-1914). Trans. Vladimir Posner Bournemouth. Inglaterra. Parkstone: Aurora Publishers.

Warnke, C. P. (2002). Picasso. Slovenia: Taschen $\mathrm{GmbH}$.

Winnicott, D. (1974). "El temor al derrumbe". Revista de APDEBA, IV, 2, (1982, artículo póstumo), pp. 111-121.

Zervos, C. (1935). "Conversation avec Picasso". París: Cahiers d’art, pp. 7-10.

\section{INTERNET}

Freud, S. (1917). Duelo y melancolía. Santiago: Edición electrónica de www.philosophia.cl /Escuela de Filosofía Universidad ARCIS. Recuperado de: http://www.philosophia.cl/biblioteca/ freud/1917Duelo\%20y\%20melancol\%EDa.pdf

Picasso, P. (1901). La Muerte de Casagemas, óleo sobre tela, París: Musée National Picasso de París. Recuperado de: http://www. eternelseclairs.fr/images/peinture/tableaux/pablo-picasso/ pablo-picasso-la-mort-de-casagemas.jpg / http://www.museepicasso.fr/pages/page_id18528_u112.htm

Picasso, P. (1901). Casagemas en su ataúd, óleo sobre tela, colección particular. Recuperado de: http://pintura.aut.org/ SearchProducto?Produnum $=32265$

Picasso, P. (1901). Evocación, El entierro de Casagemas, óleo sobre tela, París: Musée d’Art Modérne de la Ville de
París. Recuperado de: http://historiadelartecbe.blogspot. com/2012/06/picasso.html / http://es.wahooart.com/Art. nsf/O/8EWNNF/\$File/PABLO-PICASSO-THE-BURIAL-OFCASAGEMAS.-EVOCATION.JPG

Picasso, P. (1903). La Vida, oleo sobre tela, Cleveland: Cleveland Museum of Art. Recuperado de: http://historiadelartecbe. blogspot.com/2012/06/picasso.html

Picasso, Pablo. (1945-46). Cabeza de muerto, Piedra, colección particular. Recuperado de: http://trazosybosquejos.blogspot. com/2011/01/brassai-fotografia-los-suenos-de-la.html / http://4.bp.blogspot.com/_KoAln9yacAs/TURruTVR94I/ AAAAAAAABCw/J8-khjqQhhc/s1600/Picasso\%252C+Cabeza+de +Muerto\%252C+1943.jpg 